\title{
Forest management is driving the eastern North American boreal forest outside its natural range of variability
}

\author{
Dominic Cyr ${ }^{1^{*}}$, Sylvie Gauthier ${ }^{2}$, Yves Bergeron ${ }^{3}$, and Christopher Carcaillet ${ }^{4}$
}

Fire is fundamental to the natural dynamics of the North American boreal forest. It is therefore often suggested that the impacts of anthropogenic disturbances (eg logging) on a managed landscape are attenuated if the patterns and processes created by these events resemble those of natural disturbances (eg fire). To provide forest management guidelines, we investigate the long-term variability in the mean fire interval (MFI) of a boreal landscape in eastern North America, as reconstructed from lacustrine (lake-associated) sedimentary charcoal. We translate the natural variability in MFI into a range of landscape age structures, using a simple modeling approach. Although using the array of possible forest age structures provides managers with some flexibility, an assessment of the current state of the landscape suggests that logging has already caused a shift in the age-class distribution toward a stronger representation of young stands with a concurrent decrease in old-growth stands. Logging is indeed quickly forcing the studied landscape outside of its long-term natural range of variability, implying that substantial changes in management practices are required, if we collectively decide to maintain these fundamental attributes of the boreal forest.

Front Ecol Environ 2009; 7(10): 519-524, doi:10.1890/080088 (published online 10 Feb 2009)

$\mathbf{N}$ atural ecosystems have developed within ranges of conditions that can serve as references for setting conservation targets or assessing the current ecological integrity of managed ecosystems. Disturbance regimes are key processes in many types of ecosystems and contribute to the creation of the variety of ecological conditions that exist through both space and time (Reynolds 2002). Disturbance regimes' characteristics, including frequency, spatial extent, and severity, are particularly important in generating this natural variability at different spatial and temporal scales.

In the boreal forest, fire is the primary disturbance that creates a complex mosaic of stands of varying age, composition, and structure, within which other disturbances and processes interact. It is for this reason that many suggest that timber management strategies be based on our knowledge of the main characteristics of regional fire regimes (Hunter 1993). Managers would therefore apply what conservationists call a coarse filter that maintains key habitat attributes required by most of the ecosystem's species. In this paper, we focus on disturbance frequency, which can be expressed as the mean fire interval (MFI).

${ }^{1}$ Centre for Forest Research, Université du Québec à Montréal, Montréal, Québec, Canada *(cyr.dominic@gmail.com); ${ }^{2}$ Laurentian Forestry Centre, Canadian Forest Service, Natural Resources Canada, Sainte-Foy, Québec, Canada; ${ }^{3}$ NSERC-UQAT-UQAM Industrial Chair in Sustainable Forest Management, Université du Québec en Abitibi-Témiscamingue, Rouyn-Noranda, Québec, Canada; ${ }^{4}$ Centre for Bio-Archaeology and Ecology (UMR5059 CNRS), and Paleoenvironment and Chronoecology (EPHE), Institut de Botanique, Université de Montpellier, Montpellier, France
The MFI - defined as the mean number of years between two fires, averaged over a reference time period - is responsible for the creation of a landscape mosaic consisting of stands of different ages (Figure 1). Although some organisms simply need a long, continuous period of time to colonize and exploit a suitable habitat patch (Nordén and Appelqvist 2001), others are dependent on attributes associated with specific points along the age-class distribution of a natural fire regime. Many forest attributes are related to the time elapsed since the last fire, including tree species composition, structure, dead woody debris abundance, and amount of organic matter. In contrast to the natural disturbance regime, current management practices are usually characterized by clearcuts, with the interval systematically shorter than the MFI. Furthermore, although wildfires can affect stands of virtually any age, harvesting specifically targets older stands. These practices result in an extensive transformation of forested landscapes (Figure 1), with a great number of known and unknown consequences. The still poorly understood role of old-growth stands in natural landscapes is of particular concern (Kneeshaw and Gauthier 2003).

In this paper, we use a case study from a large and welldocumented area of the eastern part of the North American boreal forest (Figure 2). The fire history of the region for the last 300 years, along with the resulting ageclass distribution at the landscape scale, is well documented (Bergeron et al. 2004a). The MFI varied between 92 and 360 years, when partitioned into three periods delineated by substantial changes in climate and human occupation history (Bergeron et al. 2004a). This variability highlights the fact that no single MFI value can be 


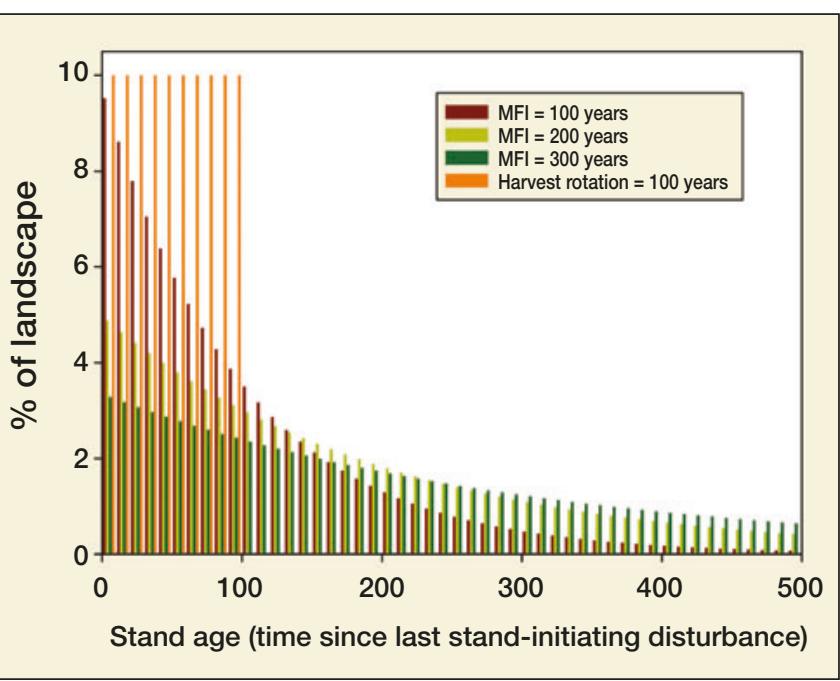

Figure 1. Landscape-scale age-class distribution under spatially and temporally constant fire regimes of varying mean fire intervals (MFIs) and under a "perfect" silvicultural system with a harvest rotation typical of the study area (100 years).

used as a unique reference. This is partly why we suggest applying a coarse filter in light of the natural variability approach.

In a review of the natural variability concepts, Landres et al. (1999) discuss the imprecision surrounding the words "natural" and "variability". To clarify this concept, they define natural variability as "the ecological conditions, and the spatial and temporal variation in these conditions, that are relatively unaffected by people, within a period of time and geographical area appropriate to an expressed goal". In this study, we use pre-European settlement conditions as a natural reference point and the age-class distribution at the landscape scale as a key attribute of primary concern in the boreal forest (Hunter 1993). However, incorporating "variability" into a management approach can be complex, because it is necessary to choose the proper spatiotemporal scales. For example, any given age-class distribution in the natural landscape is far less regular than the hypothetical ones depicted in Figure 1. This is because the fire activity in a given landscape fluctuates considerably on an interannual and interdecadal basis. It does not seem reasonable, necessary, or prudent, however, to reproduce such shortterm variations through harvesting, (1) because human communities require a relatively constant timber allocation for obvious socioeconomic reasons, (2) because unpredictable fire events will continue to occur, as fire suppression has not proven effective in the North American coniferous boreal forest, and (3) because harvesting is now systematic throughout the entire boreal forest. It is therefore unreasonable to include the same extreme scenarios everywhere at the same time, because this would compromise the ability of adjacent landscapes to serve as migration pools (eg metapopulation dynamics) should these extreme scenarios be detrimental to the needs of some species. Furthermore, the age-class distrib- ution of large landscapes (>1000 000 ha) exhibits considerable inertia, especially when the burn rates are relatively low, as is generally the case in the eastern part of the North American boreal forest. In light of modeling studies (Baker 1995), it is reasonable to suggest that the extreme MFI values of 92 and 360 years that were observed in the study area should not be used as boundaries in the context of the natural variability approach, because they applied only to several decades (Bergeron et al. 2004a). Therefore, they did not transform the longterm age-class distribution at the landscape scale. We therefore suggest that only long-term variability in the MFI, estimated from a relatively large landscape, should be considered for setting management targets under the natural variability approach.

The main objective of our paper is to translate the long-term variability in MFI, reconstructed using charcoal found in lake sediments, into a range of ecological conditions, ie the landscape-scale age-class distributions that formerly prevailed for a period of sufficient time to be used as sound and scientifically well-supported guidelines for management targets. In addition, we also endeavor to determine whether or not forest management practices have pushed the landscape away from its natural trajectory, by comparing the current state of the study area with its historical variability range.

\section{Methods}

We reconstructed a long-term fire history using sedimentary charcoal from three lakes, dated by means of ${ }^{14} \mathrm{C}$ and ${ }^{210} \mathrm{~Pb}$ isotopes (Carcaillet et al. 2001). Only charcoal fragments larger than $150 \mu \mathrm{m}$ were considered, because particles of this size generally do not travel more than a few hundreds of meters from a fire (Higuera et al. 2007). Charcoal accumulation peaks were then isolated to build fire-event chronologies, beginning as far back as 7600 years before present (yr BP) for one of the lakes, although only results spanning the past 6800 years were available for all three lakes (see methods in Carcaillet et al. 2001).

These three lakes (Figure 2) were considered as a representative sample of the surroundings, and the fire intervals from all three lakes were pooled in order to estimate the MFI across the landscape. Two averaging methods, based on the two-parameter Weibull probability density distribution, were used.

The Weibull-modeled MFI is:

$$
\text { mean fire interval }=b \Gamma(1 / c+1)
$$

where $\Gamma$ is the gamma function and $b$ and $c$ are the scale and shape parameters of the Weibull distribution, respectively (Johnson and Gutsell 1994). In the first approach, the Weibull-modeled MFI of relatively constant fire regimes was calculated by detecting regime shifts using sequential $t$ tests (Rodionov 2004). To perform these 


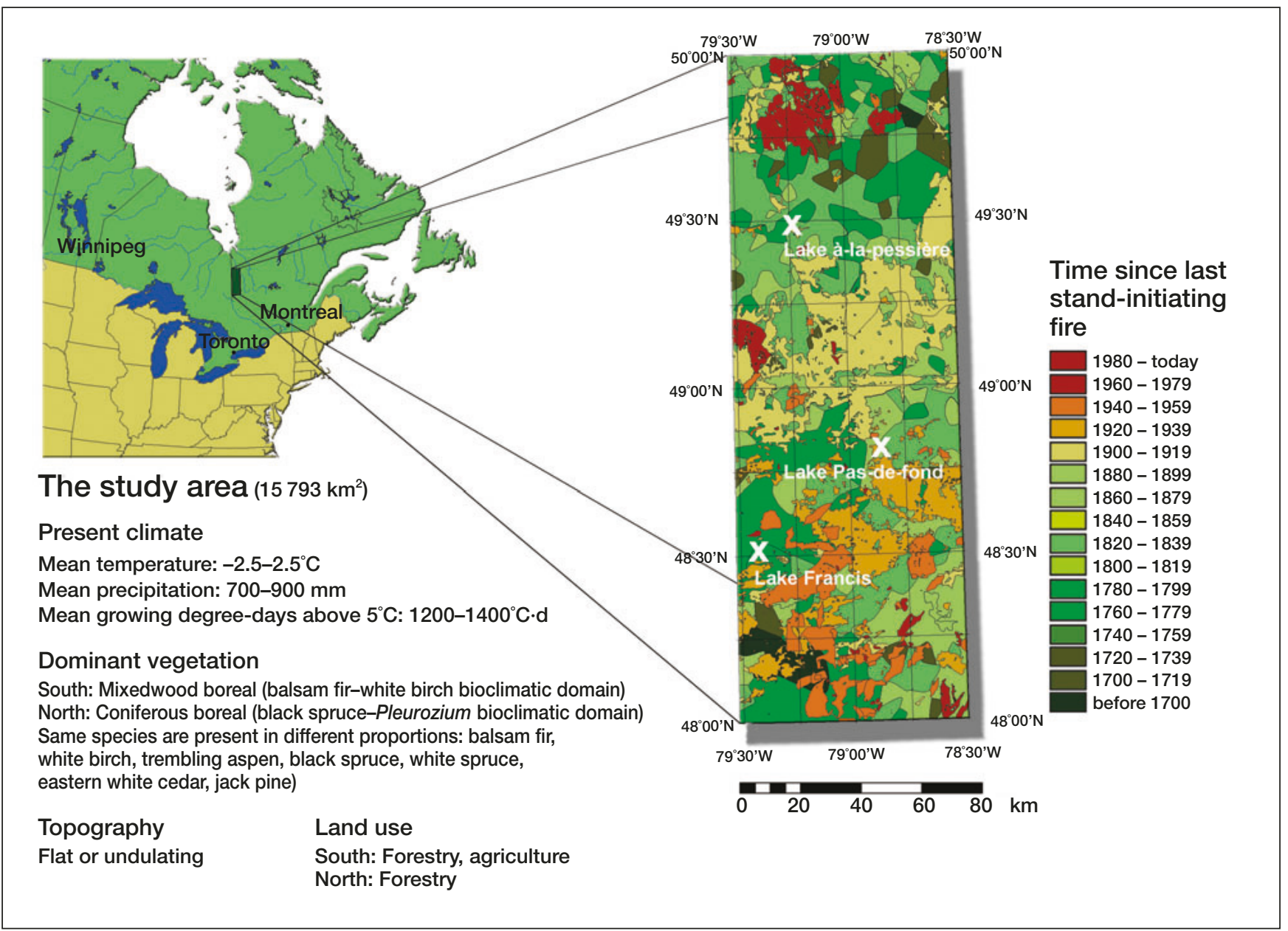

Figure 2. General description of the study area.

sequential $t$ tests, we transformed fire intervals into number of fires per century, because Rodionov's algorithm was originally intended for discrete, annually resolved datasets. A 1000-year equivalent cutoff length, which determines the minimum length of the regimes, as well as a $5 \%$ significance threshold, were used for regime shift detection. For relatively constant regimes, 95\% confidence intervals were also reported (cf WebFigure 1 for distribution fitting). The second approach was a smoothing method, which we used to fit the Weibull distribution within a moving window of 13 observations and reported the estimated MFI along our time series. This moving window roughly corresponded to a little more than 1000 years during periods with low fire frequency and about 300 years during periods with high fire frequency. We estimated the Weibull distribution parameters and 95\% confidence intervals using the LIFEREG procedure in SAS 9.1 by means of maximum likelihood.

The fire interval distributions and 95\% confidence intervals within relatively constant regimes are used for establishing management targets based on long-term natural variability in MFI. The smoothing method, which is more influenced by extreme values, is only reported for comparative purposes.

To translate the range of MFI variability into corre- sponding ranges of age-class representation, we used the cumulative form of the Weibull distribution, which derives from Johnson and Gutsell (1994), such that:

$$
A(t)=e^{-(t / b)^{c}}
$$

where $A$ is the cumulative proportion of the landscape that is younger than a given number of years $(t)$, and $e$ is the base of the natural logarithm.

To estimate the proportion of the landscape comprised within a given age class, we calculated:

$$
A\left(t_{2}\right)-A\left(t_{1}\right)
$$

where $t_{1}$ and $t_{2}$ are number of years corresponding to the boundaries of the age class of interest. We chose to use the negative exponential distribution, the simpler case of the Weibull distribution, where $c=1$, because this parameter was not significantly different from 1 in either one of the periods of relatively constant regimes (WebFigure 1). In more concrete terms, this means that the probability of fire is considered as spatially and temporally constant in the following steps of our procedure.

To assist in distinguishing between stages of silvicul- 


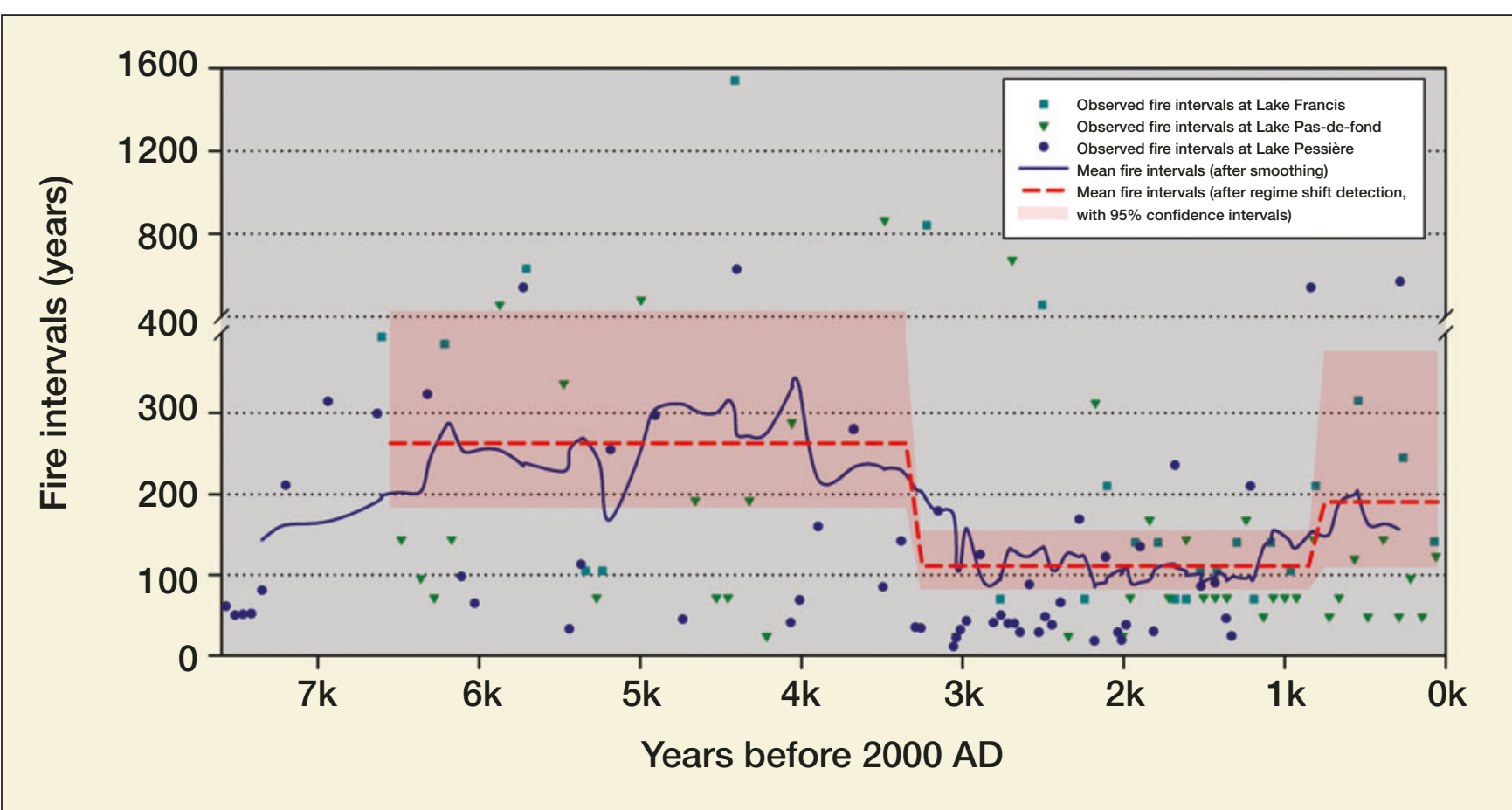

Figure 3. Fire intervals observed during the past 7600 years reconstructed from charcoal obtained from stratified lake sediments. The conservative range (from constant regimes; red dashed line) covers from 111-267 years, and the extended range (from 95\% confidence intervals; light red area) covers from 82-419 years.

tural and conservation relevance (Oliver and Larson 1996), we used large age classes, ie regenerating (0-40 yr old), young closed-canopy (41-80 yr old), mature (81-100 yr old), and over-mature and old-growth stands $(\geq 101 \mathrm{yr}$ old $)$. The definition of the age classes was also constrained by the information available in the most recent provincial data (for the province of Quebec; Bureau du Forestier en chef 2007) used to estimate the current age-class distribution in the managed portion of the landscape. This information from three different management units was compiled and weighted accordingly to the proportion of the area they respectively occupy.

Situations where the current landscape conditions are within the range covered by periods of relatively constant regimes were considered as an "acceptable" management target. This range is referred to as a conservative range of variability. Situations where the age-class representation was outside this range of variability but within the $95 \%$ confidence intervals were considered to be "of concern" although these situations likely occurred during the postglacial history of this landscape, they were probably uncommon and did not last for long periods. They are therefore considered as extremes, which are not appropriate as targets for a coarse-filter approach. Finally, situations where the age-class representations were outside this extended range of variability were considered as ecologically "unacceptable", since these situations are not representative of natural landscape states that persisted for a substantial period of time. In the last two cases, it is advisable that management actions be undertaken to bring the age-class representations back within the conservative range of variability. To be cautious, we suggest the conservative range as the one to favor for setting age-class distribution management targets, with the extended range of variability being kept for "maneuvering room" in the eventuality of unpredictable events, such as natural disturbances.

\section{Results and discussion}

\section{Long-term variability in fire activity and age-class distribution at the landscape level}

Sedimentary charcoal records show a strong variability in the MFI during the past 6800 years (Figure 3). The period between 6800 and $3200 \mathrm{yr}$ BP was characterized by a relatively long MFI, whereas the period after $3200 \mathrm{yr}$ BP shows a shorter MFI with slightly longer intervals during the past millennium (Figure 3). Climatic drivers are currently the most plausible explanation for these changes, because pollen records show no clear relationships between vegetation flammability, based on species assemblages, and fire activity during this period (Carcaillet et al. 2001).

Consequently, the age-class distribution at the landscape level also varied considerably (Figure 4), especially the proportions of over-mature and old-growth stands ( $\geq 101 \mathrm{yr}$ old; Figure $4 \mathrm{~b})$ as well as the young forests ( $0-40$ yr old). This first appears to be a good result from a management perspective, because it allows for some flexibility.

Using the most recent provincial data (for the province of Quebec; Bureau du Forestier en chef 2007), we estimate that none of the current age-class representations fall 

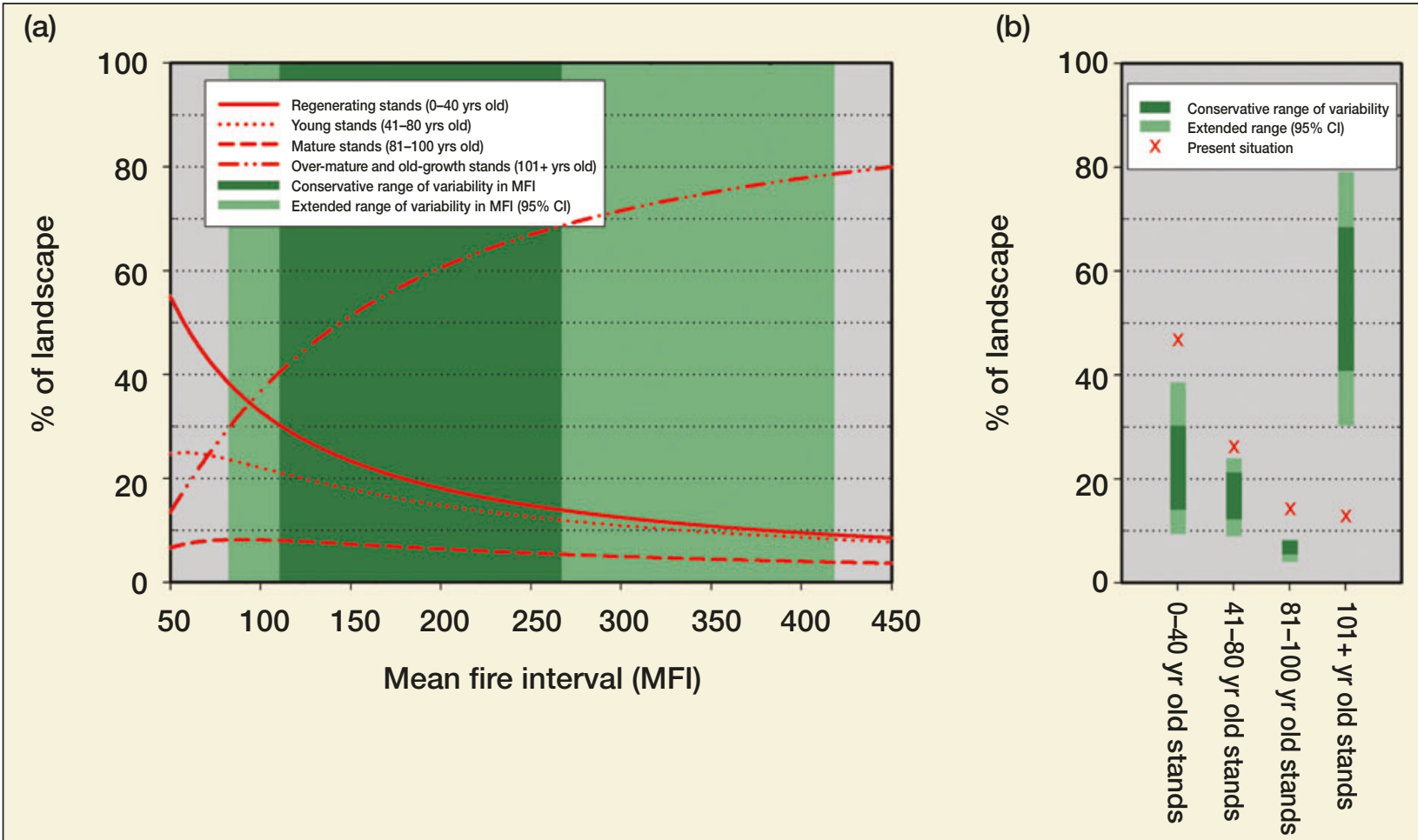

Figure 4. (a) Proportions occupied by each age class modeled under varying MFI. (b) Management targets for age-class representation following the natural variability approach. An estimate of the current representation of each age class within the landscape is provided for comparative purposes. Note that the relative abundance of age classes is also influenced by the time frame they cover, because some age classes are wider than others.

within the suggested targets, because they are all outside the extended range. There is a very high over-representation of younger age classes as compared to our estimated ranges of natural variability. In fact, under the natural fire regime, regenerating stands rarely comprised more than $30-38 \%$ of the landscape, whereas it currently covers about $47 \%$. This change provides strong empirical evidence of how fast extensive harvesting with modern methods can modify the age-class distribution at the landscape scale, seeing that mechanized harvesting only began during the 1970s. The relatively low fire frequency that was observed during this period (Bergeron et al. 2004a) further supports this assertion. The selective nature of harvesting that specifically targets older successional stages - as opposed to fire, which generally affects all successional stages - explains why the transformation of the landscape is happening much faster than what would result from a comparable natural disturbance rate. The concurrent decline in over-mature and oldgrowth stage representation may have strong effects on biodiversity.

\section{Management implications and conclusions}

Our knowledge of the biodiversity associated with overmature and old-growth stages is rather limited in the North American boreal forest, when compared with that of the Fennoscandian boreal (mainly Sweden and Finland) or temperate forests. The consequences of the ongoing reduc- tion of these late-successional stages are therefore difficult to predict. Birds and mammals rarely seem completely restricted to late-successional stages, although some species reach their peak abundance in such stands (Drapeau et al. 2003; Fisher and Wilkinson 2005). Poorly known taxa such as lichens, mosses, and soil-dwelling arthropods, which make up a very large part of the boreal biodiversity, are probably the most affected. Furthermore, despite clear differences in their respective anthropic histories, the eastern North American boreal forest and the Fennoscandian boreal forest are more similar than previously thought (Imbeau et al. 2001), because the long MFI that characterizes their respective natural fire regimes (Carcaillet et al. 2007) allows for a substantial portion of the landscape to exceed the age limit for the typical harvesting rotation. European foresters have almost completely eliminated old forests from their landscapes as a result of their longer logging history (WWF 2003). It is estimated that around 50\% of Fennoscandian IUCN (International Union for the Conservation of Nature and Natural Resources) red-listed species are threatened as a result of forestry practices that have greatly reduced the range of ecological conditions (Berg et al. 1994), mainly by decreasing the amount of oldgrowth stands in the landscapes. The example of Fennoscandian forestry, which is undoubtedly a model of performance in terms of timber production in a boreal system, should perhaps also be seen as a source of mistakes to be avoided for future wildlife management. 
The almost ubiquitous influence of fire throughout the boreal forest has fostered a false perception of unlimited resilience vis-à-vis these dramatic disturbances. However, this quality has been abused to justify the systematic use of clearcuts with relatively short rotations. Historically, MFIs have not been so short as to considerably limit the presence of over-mature and old-growth stands, at least in the eastern part of the North American boreal forest. Indeed, late-successional stands are naturally quite abundant in this part of the continent, having consistently made up more than $40 \%$ of the landscape throughout most of the postglacial history (Figure 4). Furthermore, western Quebec's forested landscape has always been more diverse in terms of age-class distribution than what is currently aimed at with current forest management; this pattern is probably similar throughout most boreal regions. Clearcuts performed with rotations systematically shorter than the MFIs are unquestionably creating younger landscapes and are consequently diminishing the proportion of over-mature and old-growth stands well below their historical abundance. This trend threatens the biodiversity associated with these stands. Considerable changes in our management practices are needed. Practically speaking, at least $40 \%$ of the landscape should be subject to one of three strategies: longer rotations (Burton et al. 1999); silvicultural treatments closer to smaller-scale disturbance dynamics, such as partial cutting (Bergeron 2004); or conservation measures. The chosen approach and the actual proportion of the landscape subject to each treatment would vary as a function of the regional forest's dynamics and fire regime characteristics.

Finally, we suggest that the long-term variability in MFI obtained from paleoecological reconstructions (eg Figure 3 ) is the most relevant data source for providing boreal forest management guidelines based on the natural variability approach. It is particularly pertinent because it encompasses a long history of varying ecological conditions and acknowledges the resilience of the boreal forest when faced with disturbance regime changes. However, the deviation from the natural conditions that was caused by extensive harvesting has the potential to negatively impact biodiversity. When long-term data are not available, a potential compromise appears to be the use of the average time since fire observed in a landscape, because it has been shown to encapsulate in a single value the variation in fire frequency over a 300-400-year period. This approach can be used in the eastern boreal forest, where the current fire frequency is lower than the historical one (Bergeron et al. 2004b).

\section{Acknowledgements}

We thank A Leduc, M Girardin, and S Daigle for helpful discussions and comments, as well as P Jasinski, P Cheers, and A Hibbert for linguistic revision. This work was supported by a Natural Sciences and Engineering Research Council of Canada discovery grant to YB and a Sustainable Forest Management Network grant to YB and SG.

\section{References}

Baker WL. 1995. Long-term response of disturbance landscapes to human intervention and global change. Landscape Ecol 10: 143-59.

Berg A, Ehnström B, Gustafsson L, et al. 1994. Threatened plant, animal, and fungus species in Swedish forests: distribution and habitat associations. Conserv Biol 8: 718-31.

Bergeron Y. 2000. Species and stand dynamics in the mixed woods of Quebec's southern boreal forest. Ecology 81: 1500-16.

Bergeron Y. 2004. Is regulated even-aged management the right strategy for the Canadian boreal forest? Forest Chron 80: 458-62.

Bergeron Y, Gauthier S, Flannigan M, and Kafka V. 2004a. Fire regimes at the transition between mixedwood and coniferous boreal forest in northwestern Quebec. Ecology 85: 1916-32.

Bergeron Y, Flannigan M, Gauthier S, et al. 2004b. Past, current and future fire frequency in the Canadian boreal forest: implications for sustainable forest management. Ambio 33: 356-60.

Bureau du Forestier en chef. 2007. Possibilité forestière 2008-2013 résultats régionaux - unité d'aménagement forestier 082-51, 085 51, 086-51. www.forestierenchef.gouv.qc.ca/resultats.asp. Viewed 15 Aug 2007.

Burton PJ, Kneeshaw DD, and Coates KD. 1999. Managing forest harvesting to maintain old growth in boreal and sub-boreal forests. Forest Chron 75: 623-31.

Carcaillet C, Bergeron Y, Richard PJH, et al. 2001. Change of fire frequency in the eastern Canadian boreal forests during the Holocene: does vegetation composition or climate trigger the fire regime? J Ecol 89: 930-46.

Carcaillet C, Bergman I, Delorme S, et al. 2007. Long-term fire frequency not linked to prehistoric occupations in northern Swedish boreal forest. Ecology 88: 465-77.

Drapeau P, Leduc A, Bergeron Y, et al. 2003. Les communautés d'oiseaux des vieilles forêts de la pessière à mousses de la ceinture d'argile: problèmes et solutions face à l'aménagement forestier. Forest Chron 79: 531-40.

Fisher JT and Wilkinson L. 2005. The response of mammals to forest fire and timber harvest in the North American boreal forest. Mammal Rev 35: 51-81.

Higuera PE, Peters ME, Brubaker LB, and Gavin DG. 2007. Understanding the origin and analysis of sediment-charcoal records with a simulation model. Quat Sci Rev 26: 1790-1809.

Hunter MLJ. 1993. Natural fire regimes as spatial models for managing boreal forests. Biol Conserv 65: 115-20.

Imbeau L, Mönkkönen M, and Desrochers A. 2001. Long-term effects of forestry on birds of the eastern Canadian boreal forests: a comparison with Fennoscandia. Conserv Biol 15: 1151-62.

Johnson EA. 1992. Fire and vegetation dynamics: studies from the North American boreal forest. Cambridge, UK: Cambridge University Press.

Johnson EA and Gutsell SL. 1994. Fire frequency models, methods and interpretations. Adv Ecol Res 25: 239-87.

Kneeshaw D and Gauthier S. 2003. Old-growth in the boreal forest: a dynamic perspective at the stand and landscape level. Environ Rev 11: S99-S114.

Landres PB, Morgan P, and Swanson FJ. 1999. Overview of the use of natural variability concepts in managing ecological systems. Ecol Appl 9: 1179-88.

Nordén B and Appelqvist T. 2001. Conceptual problems of ecological continuity and its bioindicators. Biodivers Conserv 10: 779-91.

Oliver CD and Larson BC. 1996. Forest stand dynamics. New York, NY: John Wiley and Sons.

Reynolds CS. 2002. Ecological pattern and ecosystem theory. Ecol Model 158: 181-200.

Rodionov SN. 2004. A sequential algorithm for testing climate regime shifts. Geophys Res Lett 31: L09204. doi:10.1029/ 2004 GL019448.

WWF (World Wildlife Fund). 2003. State of Europe's forest protection. Vienna, Austria: World Wildlife Fund. 